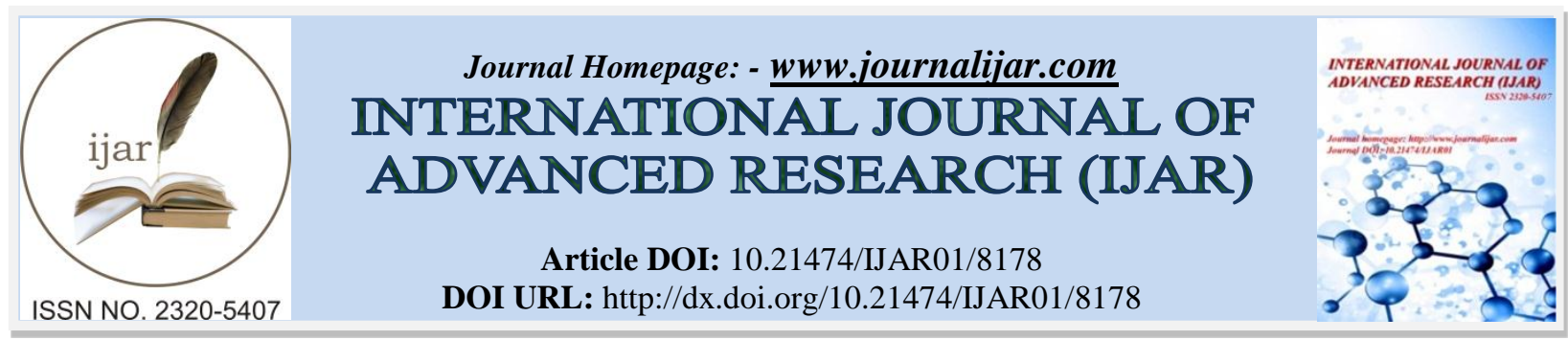

RESEARCH ARTICLE

\title{
CHARACTERIZATION OF PLASMA JET EQUIPMENT USED IN THE TREATMENT OF AESTHETIC AFFECTIONS.
}

\begin{abstract}
Angelo Roncalli Oliveira Guerra, Eneida De Morais Carreiro, Fábio Dos Santos Borges, Liliane Santos De Vasconcellos, Marla Monarrara Rodrigues Nunes, Julio Costa Silva,Patrícia Froes Meyer, Rayssa Fontes Guerra, Rodrigo Marcel Valentim Da Silva And Ivan Alves De Souza.
\end{abstract}

\section{Manuscript Info}

Manuscript History

Received: 08 October 2018

Final Accepted: 10 November 2018

Published: December 2018

\begin{abstract}
Currently, health professionals, more specifically in the aesthetic area, use various forms of energy-based technologies to improve the appearance of body and skin, and due to the proliferation of businesses involving the sale of plasma jet pens for aesthetic use around the world, doubts arose as to the veracity of information about the production or non-production of plasma by this type of equipment. Therefore, this study sought to analyse the characteristics and parameters of some electric arc plasma jet pens used in the market. It was verified that the studied plasma jet pens produced plasma in a filament regime with an unstable pen and generated only three chemical species: Nitrogen $\left(\mathrm{N}_{2}\right)$, Hydroxyl $(\mathrm{OH})$ and ozone $\left(\mathrm{O}_{3}\right)$ isotopes; however, the general physiological effects from plasma chemical species appear to be impaired by the fact that the plasma generated by most pens is quite unstable, and the thermal effect of the electric arc created to generate the plasma may cause skin burn appearance in a few seconds; the skin burns even before the full plasma action. It was concluded that the studied pens may even be sold as "plasma jet" equipment, for their plasma production; however, due to the filamentary and unstable character of the plasma found during the operation of such pens, the authors emphasize that professionals may not be able to benefit from the general physiological effects of the main chemical species of a plasma. Thus, the superficial skin carbonization effect remains to be a therapeutic action of these pens.
\end{abstract}

Copy Right, IJAR, 2018,. All rights reserved.

\section{Introduction:-}

Currently, there are some resources that may be used to benefit the skin, producing interesting results by stimulating the production of collagen and elastic fibres, improving sun-damaged skin, levelling wrinkles and skin surface. There is also a new way to perform such treatment, which uses one type of chemical species produced by an ionized gas: the plasma. In practice, the new resource is used in the form of "plasma jet pen" and it is already available in the market.

The term "plasma" is widely described in literature as being the $4^{\text {th }}$ state of matter, in which a certain gaseous substance receives a certain amount of energy and is partially ionized [1,2,3]. This ionization usually occurs in the

\section{Corresponding Author:-Rodrigo Marcel Valentim da Silva.}


presence of a source that generates a high-voltage electric field that overcomes the medium's dielectric strength (i.e. insulating barrier of a gas or solid material), and induces an electric discharge, causing that energy received by the gas to promote layer changes to the electrons and/or causes total detachment of their original atoms, inciting new successive collisions within the same medium-generating photons (light). When the collisions density between the electrons is low, the gaseous pen in the atmospheric temperature, cold plasma is formed. In the opposite case, that is, in the existence of high density of electrons implying in many collisions, the pen heats up and hot plasma is formed [4].

There are several types of gases that can generate plasma, such as helium, argon, pure nitrogen, and atmospheric air [5]. The term Plasma Skin Regeneration (PSR) arose in 2005, when the FDA authorized the use of atmospheric plasma with nitrogen for skin regeneration for rejuvenation and wrinkles treatment [6].

The plasma therapy has several applications in aesthetics. The plasma "regeneration" of the skin, in filamentary regime, common in the "pens" of plasma jet, happens due to the production of heat, inducing the thermal "damage" in the superficial skin, also causing new collagen production, elastic fibres modification, and dermis restructuring [7-10]. It is also known that other atmospheric plasma chemical species, such as hydroxyl ion $(\mathrm{OH})$ and ozone $\left(\mathrm{O}_{3}\right)$ may act as bactericide for repairing ulcers, wounds, postoperative, disinfecting the skin, among other actions. The antimicrobial effect of plasma has been used for decades to sterilize all types of tissues and materials. When the socalled "cold plasma" (pen at room temperature) is used, the low plasma temperature allows the treatment of pathogens directly on the skin, also acting as an anti-inflammatory and anti-cortical agent [3]. According to some authors [11], atmospheric plasma can also accelerate blood clotting by serving in situations that include postsurgical, post-cutaneous dermatology and therapeutic procedures involving bleeding. These authors also reported that the use of cold plasma promotes blood clotting faster than natural coagulation.

Atmospheric plasma also appears in literature as a skin hydrophilicity facilitator [12], and this could be used in the pre-cosmetic facial procedure for the cosmetic skin hydration. The use of cold plasma has facilitated the permeation of various substances (nanoencapsulated or not) in several scientific experiments [2,13-16]. This plays a significant role in enhancing the effects of various products available in the cosmetic market.

The use of plasma application by means of pens that use electric arc production to ionize the gases contained in the atmosphere has made this technology easily accessible, making plasma a very attractive therapy for applications in various affections found in dermatology and aesthetics [3,17-19]. As it is relatively new, its scientific evidence regarding application in dermatology and aesthetics is still scarce. Clarification from the manufacturers regarding the electro-electronic parameters used in their manufacture, their mechanism of action and biological and physiological effects still lack, and they also differ according to pen models and plasma production mechanism. Scientific reports and studies aimed at the analysis of commercial pens that detail the chemical species present in the plasma, frequency, voltage and/or information that identify their plasma regime are not available in literature. Therefore, this study sought to analyse the characteristics and parameters of some electric arc plasma jet pens used in dermatology and aesthetics. Such data may increase the knowledge regarding this technology by characterizing the structure and operation of some pens, seeking to facilitate professional performance with this type of equipment.

\section{Methodology:-}

The methodology applied in the study of produced plasma composition of the studied set of pens consisted in the obtention of a random sample of equipment according to market availability and taking, followed by information obtention regarding voltage, current type, frequency, production, or non-production of plasma during its operation, and the active species present in produced plasma.

Electrical voltage measurements of current type and frequency were obtained using a Keysight dsox2002a, $70 \mathrm{MHz}$, 2-channel analogue oscilloscope that allows the obtention of up to 1 Mpts of memory and 1 million waves per second, along with a probe Voltage Probe (High Voltage 1000: 110 KV 50 MHz Model IEC61010-1).

The optical emission spectrometer provides information on the intensity and wavelength of the light source produced by the plasma. Optical Emission Spectroscopy (EEO) data were obtained from an Ocean Optics USB40000 UV-VIS model spectrometer, which has an optical resolution of 0.1 to $10 \mathrm{~nm}$ (FWHM). The material used is shown in figure 1. 


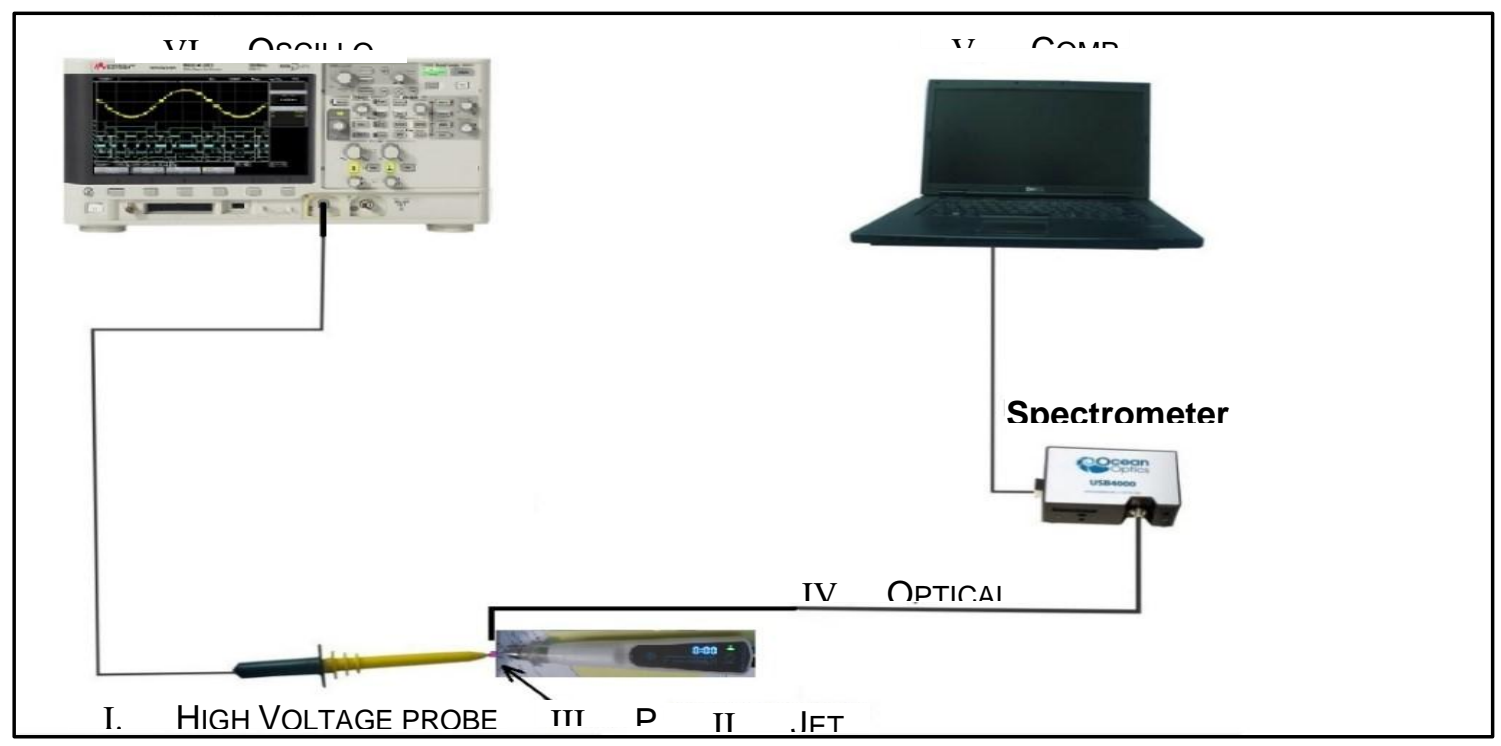

\section{Results:-}

Results were presented regarding the chemical species found in the plasma generated by the set of pens, as well as their internal energy sources frequency and voltage values for plasma production. It is important to mention that the results found in this research corroborated with those published in scientific literature for plasma DBD (i.e. Dielectric Barrier Discharge) using atmospheric air $\left(78 \% \mathrm{~N}_{2}\right.$ and $\left.21 \% \mathrm{O}_{2}\right)$ as plasma-generating gas. Table 1 shows all evaluated sets and some of their relevant characteristics.

\begin{tabular}{|c|c|c|c|c|c|c|c|}
\hline Model & $\begin{array}{c}\text { Country of } \\
\text { origin }\end{array}$ & $\begin{array}{c}\text { Number } \\
\text { of Tips }\end{array}$ & $\begin{array}{c}\text { Plasma } \\
\text { Levels }\end{array}$ & $\begin{array}{c}\text { Types of } \\
\text { Plasma }\end{array}$ & Grouding & $\begin{array}{c}\text { Registration } \\
\text { at ANVISA* }\end{array}$ & Reduced Image \\
\hline A & Rep. Tcheca & 04 & 08 & $\begin{array}{c}\text { Diffuse or } \\
\text { filament }\end{array}$ & Yes & Yes & \\
\hline B & China & 02 & 03 & Filament & No & No \\
\hline C & China & 02 & 06 & Filament & No & No \\
\hline D & China & 02 & 05 & Filament & No & No & \\
\hline E & China & 02 & 17 & Filament & No & No & \\
\hline F & Coréia & 04 & 08 & Filament & No & No & \\
\hline G & China & 04 & 09 & Filament & Yes & Yes & \\
\hline
\end{tabular}

(* Agência Nacional de Vigilância Sanitária - Brasil)

Table 1:-Characterization of pens.

In this context, it was observed that pens $\mathrm{A}$ and $\mathrm{F}$ deserved prominence for their characteristics. For this reason, they had their results detailed and grouped in a subgroup named Subgroup V. In this subgroup the preponderant element generating the plasma was the voltage. Similarly, pens B, C, D, E, and G were gathered as another subgroup, RF, as the plasma energy sources of these pens fall within a radiofrequency that ranged from 3 to 300 billion Hertz. In addition, the energy's main element source, which is responsible for plasma production in this group, is the frequency rather than the voltage. The voltage in this subgroup was not high and, therefore, it was unable to break the air dielectric barrier. Then, the average voltage and frequency results were obtained for all pens, and then the pens spectra of RF Subgroup and Subgroup V were obtained. 
Before working with the aforementioned subgroups, it is important and pertinent to present the results of the energy sources voltage and frequency general averages of all the focus pens considered in this study. These results are described in Table 2.

\begin{tabular}{|c|r|r|r|c|}
\hline \multicolumn{1}{|c|}{ Pens } & Voltage (V) & Frequency (Hz) & Reduced Image & Subgroup \\
\hline A & 1.142 & 59 & & $\mathrm{~V}$ \\
\hline $\mathrm{B}$ & 364 & 205.446 & & $\mathrm{RF}$ \\
\hline $\mathrm{C}$ & 281 & 191.372 & & $\mathrm{RF}$ \\
\hline $\mathrm{D}$ & 257 & 315.240 & & $\mathrm{RF}$ \\
\hline $\mathrm{E}$ & 1.450 & 23.250 & & $\mathrm{RF}$ \\
\hline $\mathrm{F}$ & 1.310 & & & $\mathrm{~V}$ \\
\hline $\mathrm{G}$ & 5.550 & 454 & & $\mathrm{RF}$ \\
\hline
\end{tabular}

Table 2:-Voltage and frequency averages of the sources of the plasma jet pens and their subgroups.

The results listed in Table 2 show that, for all pens of the RF Subgroup, unlike the Pens of Subgroup V, the frequency parameter alone is the source's main element responsible for plasma generation. The voltages of this group are very low; therefore, the pens are unable to overcome the air dielectric barrier and produce plasma. All frequencies are very high and in the radio frequency ranges between $191.372 \mathrm{~Hz}$ and $328.256 \mathrm{~Hz}$.

Therefore, the pens of the RF Subgroup always showed a low and alternating voltage (with sinusoidal or similar voltage wave). These pens produced a filamentary plasma with a very unstable plume (switching on and off in intermittent discharges in the presence of electric arcs) at all power levels and requiring a close approximation (about $0.1 \mathrm{~mm}$ ) between the tip of the pen and the target electrode. In a real case, this target electrode would represent the patient's skin, so if the pen tip is not too close to the skin, there is no generation of the electric arc for plasma production. It is also possible to notice that the RF Subgroup pens operate outside the expected frequency range (i.e. well above $80,000 \mathrm{~Hz}$ ) to generate DBD plasma, comparing the frequency values described in Table 2 with the findings of scientific literature.

Another important result is the observation that the plasma produced by the RF Subgroup pens may cause burns if applied to the skin of a patient. Figure 1 shows an example of the RF Subgroup, the results of the B pen with the values of voltage $(392 \mathrm{~V})$ and frequency $(247,620 \mathrm{~Hz})$.

In contrast to the RF Subgroup, the results of the Subgroup V pens based on Table 2 focus on the voltage parameter (values between $1,142 \mathrm{~V}$ and $1,310 \mathrm{~V}$ ) rather than the frequency. The value of this average voltage range shows that it is directly responsible for generating the plasma in these pens. The average of frequencies is very low and would not be significant to overcome the air dielectric barrier and produce plasma. In contrast, these pen models (Subgroup V) presented continuous and pulsed voltage that was also able to generate a diffuse plasma, with a stable pen at some power levels. Thus, plasma regimes alternated between filament and diffuse pen A and always remained filamentary in case of pen F. Lastly, the authors realized, by comparing the voltage values described in table 2 with the findings from previous scientific literature, that the pens from Subgroup V operate outside the range expected to generate plasma DBD (below 5,000V). Figure 2 shows an example of Subgroup V, with the results of pen A and voltage values $(1,890 \mathrm{~V})$ and frequency. 


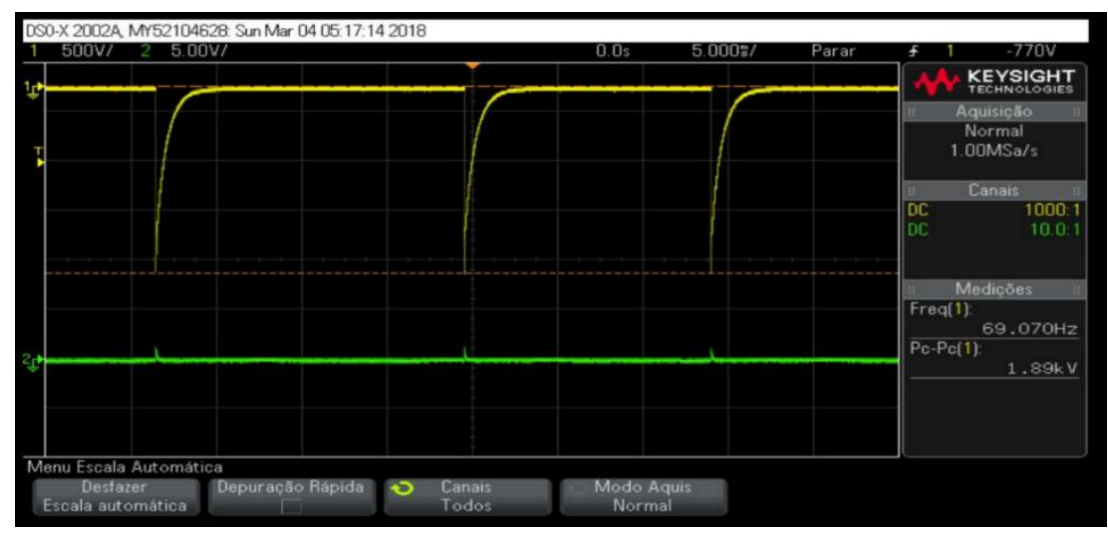

Fig 2:-Example of Voltage / Frequency measurement obtained at power level 7 for subgroup V "A" pen. Continuous pulsed voltage.

The graphs obtained for chemical species analysis and the spectra of light emission in the various pens studied were very similar, therefore, only one pen of each subgroup will be presented. The graph shown in Figure 3 shows the light emission spectrum for pen A, Subgroup V, at 8 power levels and representative of the chemical species found in the plasma produced in this subgroup.

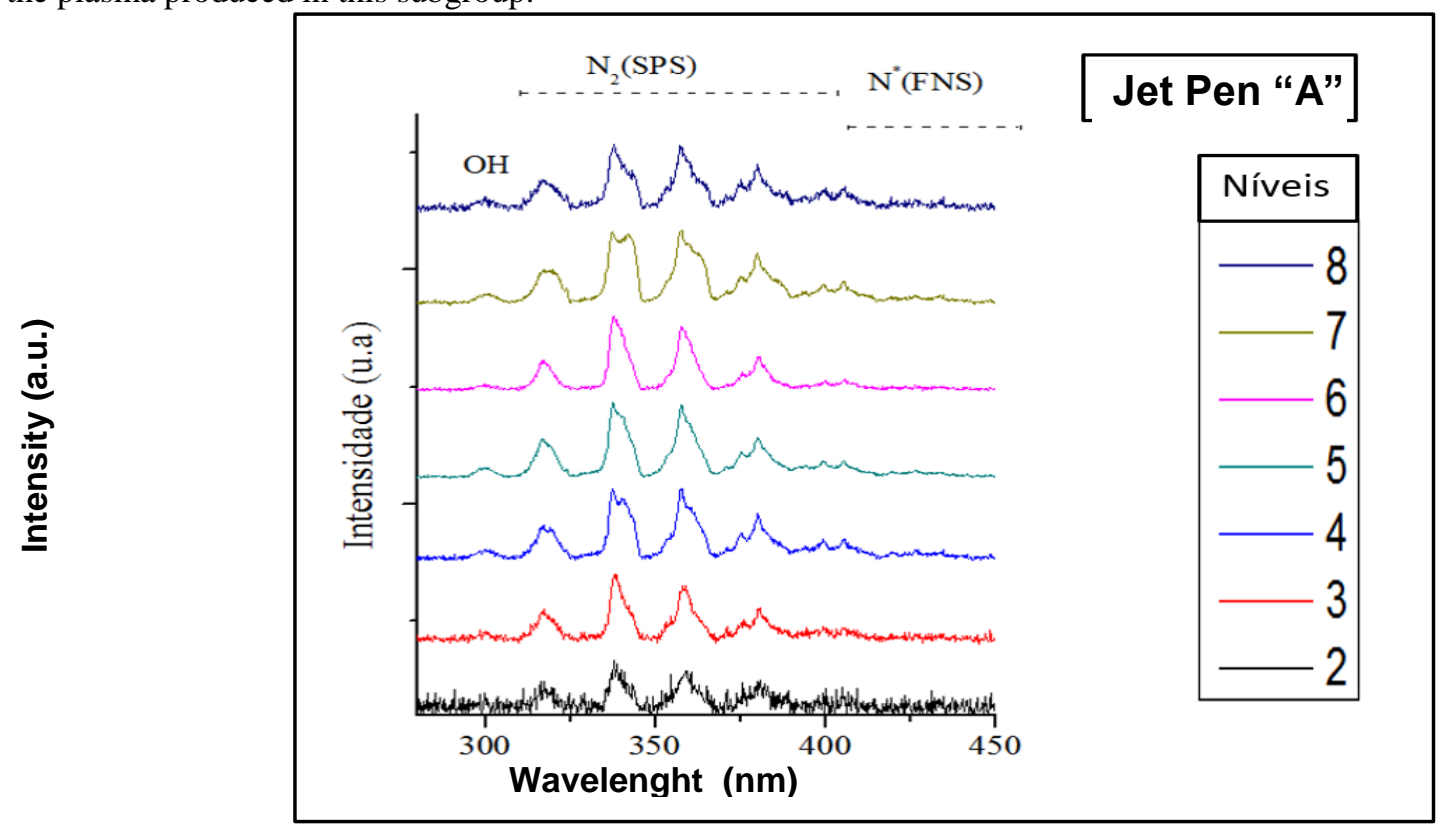

Fig 3:-Graphs of the spectrum of the chemical species produced by the plasma of pen A.

As a result of the spectrum characterization of Subgroup V, it was observed that at the lower power levels of this subgroup (e.g. level 1 of pen A) did not even generate plasma and, therefore, no chemical species were detected at this level.

The presence of hydroxyl $(\mathrm{OH})$ shown in the graph is also another important result. After all, the hydroxyl is functionally added to the ozone (another present chemical species) and is naturally released during the already known reaction of the plasma with the oxygen of the atmosphere. It is known that, although there is currently a limitation of commercial spectrometers to detect the light from ionization of the oxygen isolated and present in the air humidity $(\mathrm{H} 2 \mathrm{O})$, basically, this molecular oxygen after having been ionized (dissociated) in atomic oxygen, if recombined, later with other molecules of $\mathrm{O}_{2}$, also of the atmospheric air, forming $\mathrm{O}_{3}$. A characteristic odour of the ozone presence could easily be perceived during the operation of Subgroup V pens. 
The results concerning the chemical species detected in the light emission spectra graphs for the RF subgroup of pens were not significantly different, neither regarding Subgroup V nor between the pens within the same subgroup at Figure 4. In summary, the same chemical elements already detected in Subgroup V (i.e. Nitrogen $\left(\mathrm{N}_{2}\right)$ and Hydroxyl (OH) isotopes were also detected in the RF Subgroup pens.) There was little in the wavelengths range variation between the two subgroups and between the of the RF subgroup pens (average $295-240 \mathrm{~nm}$ ), and it was observed that closer approximation of the target electrode was required in order to generate plasmas (about $0.1 \mathrm{~mm}$ ). Part of the pens of this subgroup had only enough energy to overcome the air dielectric barrier and produce plasma at power levels greater than 3 or 4 . The same comments made for the results obtained by the EEO equipment for Subgroup V are also valid and applied to this RF Subgroup.

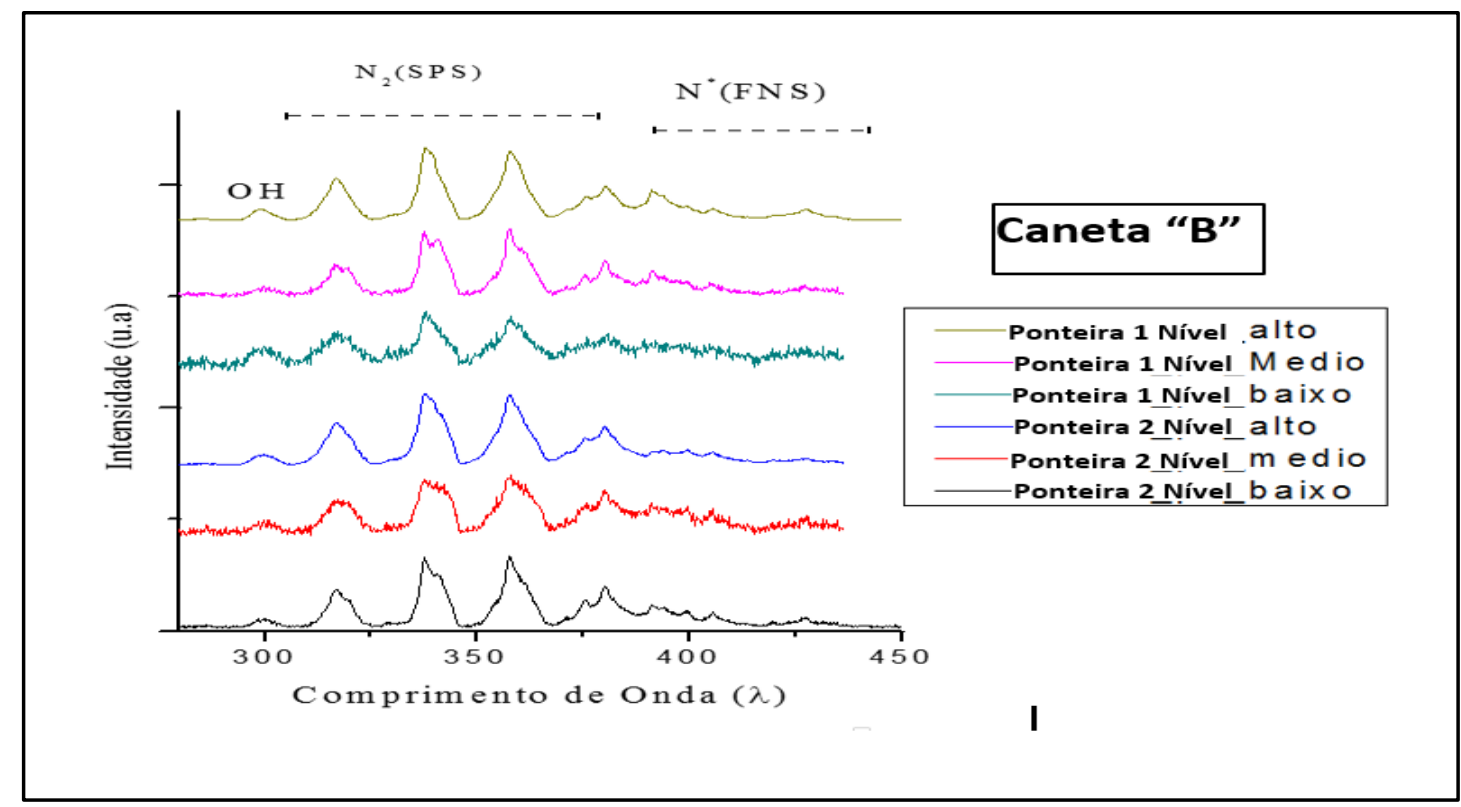

Fig 4:-Graphs of the spectrum produced by the plasma of pen B

Lastly, Figure 5 illustrated B pen's spectrum, which was the only case within RF Subgroup that was able to open plasma at all power levels. The figure also illustrates the light spectrum and chemicals species found in plasma at various levels. It is a much representative graph of the RF Subgroup.

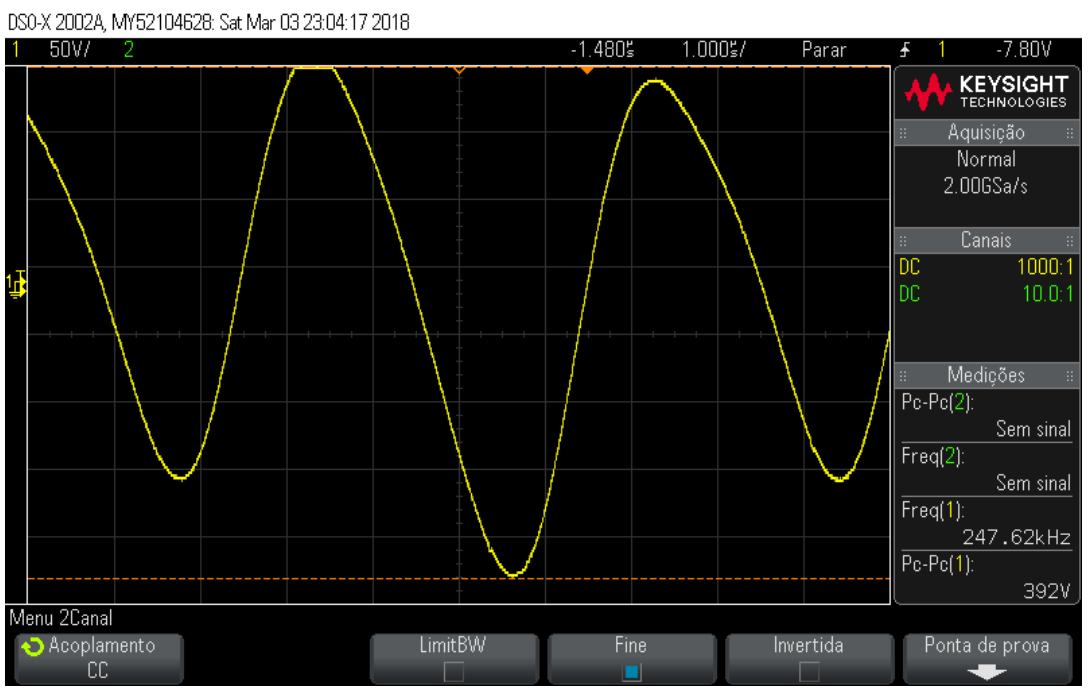

Fig. 5:-Example of Voltage / Frequency measurement at the high power level for the "B" pen belonging to the RF Subgroup. Sinusoidal Voltage. 


\section{Discussion:-}

All of the commercial atmospheric plasma jet pens that were objects of this study consisted of devices which excite the gases in their surrounding through a source of energy capable of producing a high voltage or high frequency electric field which is then applied between the tip (i.e. cathode electrode or negative pole) and skin to be treated (characterized as anode) in order to overcome the air dielectric barrier (insulator) causing an electric discharge (in the form of sparks or arcs) and generating a luminous pen-associated plasma. It is very important to keep in mind that the air (gas) between the electrodes (i.e. pen tip and skin) is a bad conductor of electricity (dielectric) and, therefore, it represents a barrier to be overcome by the energy source that also needs to beat the distance (space) between the tip and skin of the patient to allow the appearance of a luminous plasma. Thus, the longer the skin-pen distance, the greater the dielectric barrier to overcome.

Considering this context, the plasma produced by the studied pens closely resembles that described in literature with the name "Plasma DBD". The main difference is that the pens do not have the extra solid dielectric (insulation) that would be expected to be inserted in the cathode electrode (pen tip). This fact is also one of the main reasons for the instability of the plasma (plume intermittent lighting) due to the appearance of concentrated electrical discharges (arcs or filaments of sparks). The extra solid barrier of classical DBD plasmas is precisely designed to avoid arcs with consequent temperature rise. This fault also diverges from the classic concept of "Plasma DBD" which suggests plume generation at room temperature. These two observations are critical when trying to fit the plasma generated by the pens studied in the classic concept of "Plasma DBD". However, this was the nomenclature adopted in this research, due to the similarities found in the obtained results.

The studies analysed in the literature review carried out in this work show that, currently, the most used gases for the production of plasma for general applications, including industry, are: oxygen, nitrogen, argon, hydrogen, helium, and neon [6]. It is important to clarify that several scientific articles have already been published [20,21], showing that, naturally, different chemical species appear in the plasma luminous plume, depending on the type of gas that is to be used as a dielectric barrier, therefore, each specific gas jet (excited or ionized by the energy source) will produce different chemical species (cations, anions, electrons, and free radicals) capable of producing different effects on the skin for regeneration, healing, immune system stimulation, proliferation, and collagen remodelling.

It is somewhat surprising that, in this research, none of the pens used any of the common gases in the abovementioned literature as a dielectric barrier in which a high purity and very well-controlled gas flow is assumed. In fact, all the pens indeed adopt a gaseous mixture, that is, they use the atmospheric air itself as a dielectric barrier, knowing that it is composed basically of a mixture of $78 \% \mathrm{~N}_{2}$ and $21 \% \mathrm{O}_{2}$. Therefore, whenever this mixture is used as a dielectric barrier in plasma formation, it will result in the formation of luminous plumes restricted only to chemical species derived from oxygen and nitrogen. Consequently, no effects may be expected on the treatment of cancer cells from these pens, for example, using only atmospheric air when it is already known that the concentration of argon gas) in air composition is only $0.9 \%$ of the total volume. The therapeutic effect to fight cancer may only be achieved if the argon gas is actually used as a gaseous dielectric barrier [5], and if commercially purchased in cylinders of sizes that are standardized by the industry, of high purity presentation. The flow rate also needs to be well-determined and controlled.

The results of this research showed that in all pens of both Subgroups V and RF, the excited chemical species detected in the various spectra were always the isotopes of Nitrogen $\left(\mathrm{N}_{2}\right)$ and Hydroxyl $(\mathrm{OH})$. The other chemical species that was present was ozone $\left(\mathrm{O}_{3}\right)$ that resulted from the classical chemical reactions between plasma and air oxygen. However, it is believed that, in the case of the pens listed in this study, the actions of these chemical species seem to be impaired by the fact that the plasma generated by most of them is very unstable and the thermal effect of the electric arc created to generate the plasma causes the appearance of burns on the skin within seconds. The skin burns even before the full plasma action.

There are basically two different operation regimes after the of a plasma luminous plume emergence: the filament and diffuse regime. In the filamentary regime, after the energy source overcomes the dielectric barrier, there are strong electrical discharges concentrated through filaments and/or arcs that resemble a filament of an incandescent lamp or rays on a rainy day. These filaments and arcs raise the temperature of the skin being treated causing burns. However, in the diffuse regime known as "luminescent discharge", the discharge is smoother and the plume homogeneous and stable, without the formation of arcs. The pen produced plasma plumes at room temperature 
without causing discomfort to the patient. This special operating condition is determined by the type of operating gas, electrode distance, voltage, and frequency of the voltage pulse [22].

It has been shown that most pens operated in the pure filament plasma regime regardless of the selected power level or tip used. This assertion is valid for both subgroups. The only exception was pen A which, at some voltage levels, showed diffuse and stable plasma. As previously mentioned, the filamentous plasma regime causes discomfort to the patient due to the imminence of skin burning. The diffuse plasma has the advantage of keeping the pen stable and at room temperature (Cold Plasma) being easily tolerated by the patient. In addition, it allows the patient to undergo the plasma jet treatment/session for a longer time. The filamentous plasma, even when applied to the same region of the skin for short periods, may cause severe skin damage, and may even reach the dermis at deep levels.

The filamentary operating regime of the substantial majority of the studied pens resulted in a functional performance with characteristics that are very similar to those of the electrocautery devices. The classical electrocautery corresponds to an already well-established technique used to heat and/or destroy a tissue by cells dehydration, rupture, and carbonization [23]. Within this context, despite not being the central focus of this research, it was decided that it would be interesting to superficially investigate the light emission spectrum of an electrocautery equipment with the purpose of comparing the found effects with the graphs of the various pens studied here. Thus, it was verified that the wavelength range of the electrocautery equipment (Pen E, RF Subgroup) is very similar to that of the pens from Subgroups V and RF, with values between 290 and 325 nanometres. Clearly, the same chemical species were present. Thus, undoubtedly, electrocautery equipment also produces filament plasma. The point of discussion then focused on pens that can only operate on a purely filamentary plasma regime and compare them with electrocautery equipment. This discussion may help answer the following question: why use plasma-jet pens that work on a filamentary regime if they produce exactly the same chemical species as the electrocautery equipment? With regard to the voltage values found within Subgroup V, they somewhat differ from those described in literature $[24,25]$.

The values were below the expected $5.000 \mathrm{~V}$ (in the range of $1,142 \mathrm{~V}$ to $1,310 \mathrm{~V}$ ). One possible explanation for this result is that even though this voltage range is lower, it also requires a much greater approximation (minimum of 1 $\mathrm{mm}$ ) between the pen tip and the target electrode (or skin to be treated) for plasma plume generation. That is, the voltage is lower, but the distance between the electrodes is also smaller, reducing the air dielectric (insulating) barrier.

The final discussion refers to the nature of the plasma-generating energy source: voltage and alternating current (AC) or voltage and direct current (DC). The pens of the RF Subgroup are powered by voltage and AC sources, while the pens of Subgroup V are powered by sources with voltage and direct pulsed current. From the results, sources with pulsed direct current and voltage are believed to be more likely to produce diffuse DBD plasma. This fact is justified by the fact that solid barriers tends to prevent arc formation [23-25].

In this study, six commercial plasma jet pens with application/indication in the areas of physiotherapy and aesthetics, and 01 (one) classical electrocautery equipment were studied and characterized. The main findings of the study are listed below:

1. Plasma jet pens studied to produce plasma can overcome the dielectric barrier of atmospheric air using sources of energy that present either high frequency (radiofrequency) or high voltage, and average distance between the tip of the pen and the skin of only $1 \mathrm{~mm}$;

2. Most pens produced plasma in a filament regime with an unstable pen and generating only 03 (three) chemical species, namely: Nitrogen $\left(\mathrm{N}_{2}\right)$, Hydroxyl $(\mathrm{OH})$, and ozone $\left(\mathrm{O}_{3}\right)$ isotopes;

3. The wavelength range of the excited chemical species coincided in values with the range described in literature for plasma DBD and values ranged from 290 to 450 nanometres;

4. The general physiological effects from the chemical species of plasma seem to be impaired by the fact that the plasma generated by most pens is very unstable and the thermal effect of the electric arc created to generate the plasma causes the appearance of burns in a few seconds. The skin burns even before the full action of plasma;

5. It is understood that the filament plasma regime of pens, even when applied for short periods, to the same region of the skin, may cause severe skin damage, and may even reach the dermis at deep levels;

6. The filament operating regime of the vast majority of the studied pens presents characteristics very similar to those of the classic electrocautery device, as it also produced exactly the same chemical species of the pens. 


\section{Acknowledgments:-}

The authors would like to thank prof. Clodomiro Alves Junior of UFERSA - Labplasma Laboratory for allowing the use of the spectrometer to produce the graphics presented here.

\section{Conclusion:-}

The studied pens (except those of Subgroup V), can even be sold as "plasma jet" equipment, for their plasma production capability; however, due to the filamentary and unstable character of the plasma found during the operation of such pens, the authors emphasize that professionals will not be able to benefit from the general physiological effects of the plasma main chemical species. Thus, and the superficial skin carbonization effect remains to be a therapeutic action of these pens.

\section{References:-}

1. Morfill GE, Kong MG, Zimmermann JL. Focus on Plasma Medicine. New J Phys. 2009; 11: 115011.

2. Emmert S, Brehmer F, HanBle H, Helmle A, Mertens N, Ahmed A, et al. Atmospheric pressure plasma in dermatology: Ulcus treatment and much. Clinical Plasma Medicine. 2013;1: 24-29.

3. Tiede R, Hirshberg J, Daeschlein G, Woedtke T, Viel W, Emmert S. Plasma Aplications: A Dermatological View. Contributions to Plasma Physics. 2014;54: 118-130.

4. Vilarinho LO. O arco TIG a 100 A e Argônio Puro é um Arco Especial. Soldagem e Inspeção. 2009;14: 353357.

5. Tanaka and Hori. Biomedical Application of NonThermal Atmospheric Pressure Plasma and Its Usefulness. J. Clin. Biochem. Nutr. 2017;60: 29-32.

6. Heinlin J, Morfil G, Landthaler M, Stolz W, Isbary G, Zimmermann JL, et al. Plasma medicine: possible applications in dermatology. Journal of the German Society of Dermatology. 2010;8: 968-976.

7. Bogle MA, Arndt KA, Dover JS. Evaluation of plasma skin regeneration technology in low-energy full-facial rejuvenation. Arch Dermatol. 2007;143: 168-174.

8. Fitzpatrick R, Bernstein E, Iyer S, Brown D, Andrews P, et al. A histopathologic evaluation of the plasma skin regeneration System (PSR) versus a standard carbon dioxide resurfacing laser in an animal model. Lasers Surg Med. 2008;40: 93-99.

9. Foster KW, Moy RL, Fincher EF. Advances in plasma skin regeneration. J Cosmet Dermatol. 2008;7: 169-179.

10. Holcomb JD, Kent KJ, Rousso DE. Nitrogen plasma skin regeneration and aesthetic facial surgery: Multicenter evaluation of concurrent treatment. Arch Facial Plast Surg. 2009;11: 184-193.

11. Sakakita H, Kiyama S, Koguchi H, Hirano V, Thimada S, Tokitani M, et al. Development of High-PowerDensity Ion Beam System with High-Repetition Pulse Operation. Plasma and Fusion Research. 2010;5: S2105.

12. Da Silva DLS, Farias ML, Vitoriano JO, Alves Júnior C, Torres SB. Use of atmospheric plasma in Germination of Hybanthus calceolaria (L.) Schulze-Menz. Rev. Caatinga. 2018;31: 632-639.

13. Kalghatgi S, Friedman G, Fridman A, Clyne AM. Endothelial cell proliferation is enhanced by low dose nonthermal plasma through fibroblast growth factor-2 release. Ann Biomed Eng. 2010;38: 748-757.

14. Lademann O, Kramer A, Richter H, Patzelt A, Meinke MC, Roewert-Huber J, et al. Antisepsis of the follicular reservoir by treatment with tissue-tolerable plasma (TTP). Laser Physics Letters. 2011;8: 313-317.

15. Lademann J, Patzelt A, Richter H, Lademann O, Baier G, Breucker L, et al. Nanocapsules for drug delivery through the skin barrier by tissue-tolerable plasma. Laser Physics Letters. 2011;20: 488-490.

16. Shimizu T, Stefferd B, Pompl R, Jamitzky F, Bunk W, Ramrath K, et al. Microwave plasma torch for bacterial steril-ization. 6th Int. Conf. Reactive Plasmas, Matsushima-Japan. 2006.

17. Yang Y, Xiong L, Sun J, Li Q. Treatment of Xanthelasma Palpebrarum by Upper Eyelid Skin Flap Incorporating Blepharoplasty. Aesth Plast Surg. 2013;37: 882-886.

18. Sotiris TG, Dimitris V, Goutas NG. Clinical And Histological Presentation After Plexr Application, Needle Shaping (Vibrance) And O.F.F. Pinnacle Medicine \& Medical Sciences. 2015;2: 522-530.

19. Gloustianou G, Sifaki M, Tsioumas SG, Vlachodimitropoulos, Scarano A. Article Presentation Of Old And New Histological Results After Plasma Exercises (Plexr) Application (Regeneration Of The Skin Tissue With Collagen III). Pinnacle Journal Publication. 2016;3: 983-990.

20. Ferreira WD, Grandinete YC, Lopes RB, Hermes MG. A new contribution to the knowledge of Neotropical Eumeninae. Zootaxa. 2015;3981: 117-124.

21. Prado R, Anitua E, Troya M, Zalduendo M, Fuente M, Pino A, et. al. Implementation of a more physiological plasma rich in growth factor (PRGF) protocol: Anticoagulant removal and reduction in activator concentration. Journal Platelets. 2016;27: 459-466. 
22. Souza GG. Determinação de amilorida e triantereno em plasma sanguíneo por espectrofluorimetria e calibração de segunda ordem. Dissertação de Mestrado, Universidade de Brasília. 2013.

23. Rego Filho FA, Araújo MT, Bagnato VS, Silva Júnior OC, Kurachi C, Oliveira IM, et al. Aspectos ópticos e histopatológicos do uso combinado de técnicas cirúrgicas com terapia fotodinâmica. Tese de Doutorado, Universidade Federal de Alagoas. 2013.

24. Eliasson B, Kogelschatz, U. Modeling and applications of silent discharge plasmas. Plasma Science, IEEE Transactions on. 1991;18: 309-323.

25. Wagner HE, Brandenburg R, Kozlov KV, Sonnenfeld A, Michel P, Behnke JF. The barrier discharge: basic properties and applications to surface treatment. Vacuum. 2003;71:417-436. 